Research Article

\title{
Acoustic Emission and Failure Modes for Coal-Rock Structure under Different Loading Rates
}

\author{
Ning Wang $\mathbb{D}^{1}{ }^{1}$ Yingqian $X u^{2}$ Dengyuan $Z h u,{ }^{1}$ Nan Wang, ${ }^{1}$ and Benfu Yu ${ }^{1}$ \\ ${ }^{1}$ School of Civil Engineering and Architecture, Linyi University, Linyi 276005, China \\ ${ }^{2}$ Department of Solid Mechanics, Kazan (Volga Region) Federal University, Kazan 420008, Russia
}

Correspondence should be addressed to Ning Wang; 732567220@qq.com

Received 9 August 2018; Accepted 18 September 2018; Published 14 October 2018

Guest Editor: Guo-zhong Hu

Copyright (c) 2018 Ning Wang et al. This is an open access article distributed under the Creative Commons Attribution License, which permits unrestricted use, distribution, and reproduction in any medium, provided the original work is properly cited.

Coal bump refers to a sudden catastrophic failure of coal seam and usually causes serious damages to underground mining facilities and staff. Considering the combined coal-rock structure for coal bumps, failure process and acoustic emission (AE) characteristics of combined coal-sandstone samples under different loading rates were studied by uniaxial compression tests, and three basic failure modes and bump proneness for coal-rock structure were obtained. The following conclusions are drawn: (1) when loading rate was relatively low, plastic deformation of coal mass fully developed, while surface cracks of coal mass was not apparent and slip along the transfixion crack occurred in the postpeak stage; (2) with the increase in loading rate, surface tensile cracks developed into splitting cracks at the end of the prepeak stage and throughout the postpeak stage, and brittle failure finally happened due to the release of nonlinear step-shaped energy or one-time strain energy release of upper rock mass, resulting in the damage of internal bearing structure and weakening of bearing capacity; (3) the deformation and failure process of combined samples showed obvious phases, and corresponding AE energy release rate could be divided into periodic linear growth and transient growth, while the cumulative energy of AE events has multiple peak points and transient growth with the increase of loading rate; (4) it was demonstrated that two distinct frequency bands existed in $\mathrm{AE}$ events, which were about $50 \mathrm{kHz}$ and $150 \mathrm{kHz}$, and the distribution of $\mathrm{AE}$ events near $50 \mathrm{kHz}$ was larger and stronger, representing the main frequency range of cracks in coal mass. According to the damage characteristics and AE parameters for combined samples, an brittle model for coal-rock structure with mutation characteristics was proposed, and three basic failure modes for the combined structure with the increase of loading rate were progressive shear failure, splitting failure, and structural failure, respectively.

\section{Introduction}

Coal bump refers to a sudden catastrophic failure of coal seam and coal burst into the underground mining roadway [1], with a dynamic process of sudden, rapid, and violent release of elastic energy accumulated in rock and coal masses during underground mining [2-4]. Its essence is neither pure strength failure of coal mass nor the direct result of roof convergence, but is the consequence of steady accumulation and dynamic release of elastic energy, corresponding to roof pressure loading transmission and progressive failure of coal mass under the condition of coordinated deformation. Although much effort has been made to control and mitigate coal bumps, coal bumps are still frequently reported in underground mining and even more for deep coal mining across the world [5-8].

Mechanical characteristics and failure modes of coal mass are determined by the comprehensive influence of loading conditions [9-13]. Many studies have been conducted on the effects of the combination mode on mechanical properties, failure characteristics of coal-rock combinations, and failure behavior of typical combined samples under different loading paths [14-16]. Different indexes which can reflect the relationship between energy accumulation and release of combined samples were proposed to measure bump proneness $[17,18]$. However, the influence of the loading rate on the mechanical characteristics of combined coal-rock structure has not been investigated thoroughly. 
Various kinds of monitoring information of combined samples can be obtained under different test conditions, while $\mathrm{AE}$ and microseism information can reflect the energy dissipation intensity of combined samples during the failure process $[17,19]$. The accumulation and release of elastic energy are in accordance with the rock failure process and with the assumption of damage mechanics and certain distributions obeyed by microelement strength, and corresponding statistical models have been established [20, 21]; however, the relationship between loading conditions and dynamic energy release law has not been completely obtained, and practical failure modes for combined samples measuring bump proneness have not been established.

Coal bumps frequently occur within a underground mining structure constituted by hard rock roof and relatively hard coal seam. In this paper, combined samples of coalsandstone are taken into consideration for coal bumps, and the research on uniaxial compression tests under different loading rates is carried out. According to the damage characteristics and AE monitoring information of combined samples, failure modes for combined samples are extended.

\section{Test Scheme for Combined Coal-Rock Structure}

2.1. Loading Scheme. Typical combined structure of coalrock is shown in Figure 1. In the uniaxial compression tests, the load is transferred from sandstone to rock mass in the vertical direction, and the axial strain is the sum of axial rock strain and axial coal strain. For the coal mass, it is assumed that the microelements reaching the strength lose bearing capacity immediately, and the load is transferred to the undamaged microelements, while the stress-strain relationship of the rest microelements follows the equivalent Hooke's law:

$$
\sigma=E \varepsilon(1-D)
$$

where $\sigma$ is the horizontal stress, $E$ is the elastic modulus, $\varepsilon$ is the axial strain, and $D$ is the damage variable.

Herein, the axial displacement control method is applied for obtaining postpeak stress-strain relationship. According to the performance of the testing equipment, the span of the loading rate was expected to be extended as far as possible. Five initial loading rates of $0.006 \mathrm{~mm} / \mathrm{min}, 0.012 \mathrm{~mm} / \mathrm{min}$, $0.03 \mathrm{~mm} / \mathrm{min}, 0.06 \mathrm{~mm} / \mathrm{min}$, and $0.12 \mathrm{~mm} / \mathrm{min}$ were preliminary selected. Considering preliminary test results, loading rate of $0.04 \mathrm{~mm} / \mathrm{min}$ and verification tests were then carried out. The loading condition for combined samples is shown in Table 1.

2.2. Sample Selection and Processing. In order to study the deformation and failure characteristics of combined samples, the hard anthracite [22] and roof sandstone from the No. 8937 working face in $11^{\#}$ coal seam of Xinzhou Coal Mine in Datong mining area of China were selected to conduct the experiment under natural moisture state. The uniaxial compressive strength of the roof sandstone was about $150 \mathrm{MPa}$, and the uniaxial compressive strength of the

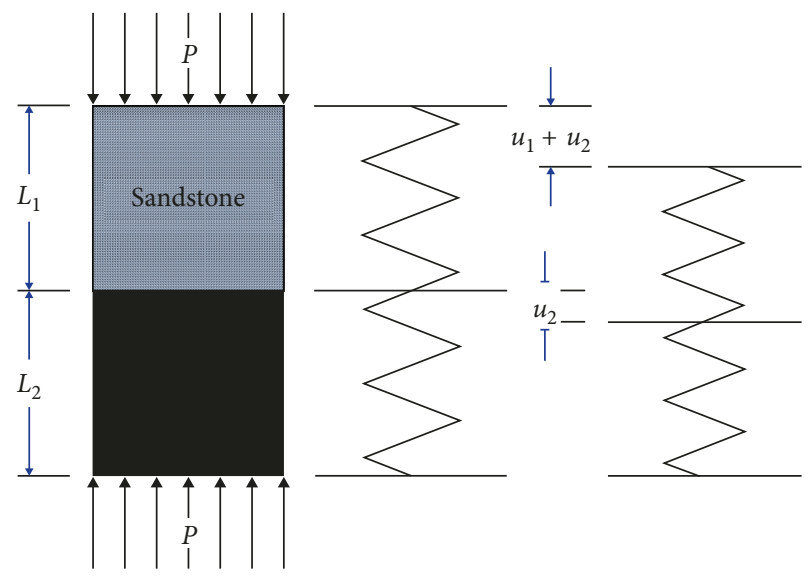

Figure 1: Combined structure of coal-rock.

TABLE 1: Loading rate of each sample.

\begin{tabular}{lccc}
\hline No. & $\begin{array}{c}\text { Loading rate } \\
\left(\mathrm{mm} \cdot \mathrm{min}^{-1}\right)\end{array}$ & $\begin{array}{c}\text { Loading rate } \\
\left(\mathrm{mm} \cdot \mathrm{s}^{-1}\right)\end{array}$ & $\begin{array}{c}\text { Strain rate } \\
\left(\mathrm{s}^{-1}\right)\end{array}$ \\
\hline 1 & 0.006 & $1 E-4$ & $1 E-6$ \\
2 & 0.012 & $2 E-4$ & $2 E-6$ \\
3 & 0.03 & $5 E-4$ & $5 E-6$ \\
4 & 0.04 & $7 E-4$ & $7 E-6$ \\
5 & 0.06 & $1 E-3$ & $1 E-5$ \\
6 & 0.12 & $2 E-3$ & $2 E-5$ \\
\hline
\end{tabular}

coal mass was about $15 \mathrm{MPa}$. The stress-strain curves of individual coal and rock samples are shown in Figure 2.

The obtained coal and sandstone blocks were processed into $\Phi 50 \mathrm{~mm}$ cylinders and then cut into corresponding samples with different lengths by stone sawing machine. Finally, the two ends of the cylinders were, respectively, polished into smooth planes by grinding machine, with the deviation control within $0.02 \mathrm{~mm}$ in diameter and the total height of each sample $100 \mathrm{~mm}$ after processing, with height ratio of sandstone to coal $1: 2$. The rock sample is put on the top and the coal sample on the bottom, as shown in Figure 3.

\subsection{Test Equipment and Data Monitoring}

2.3.1. Loading Equipment. GAW-2000 electrohydraulic servo rock triaxial testing machine.

2.3.2. Strain Acquisition Equipment. The dynamic recording system of the testing machine was combined with a standard $50 \times 100 \mathrm{~mm}$ strain extensometer to measure overall axial stain, and the axial strain of the coal and rock was recorded by the strain gauges in the upper part and the lower part of the sample, respectively.

2.3.3. AE Collection Equipment. AE probes were fixed on the upper sandstone of combined sample and parameters of $\mathrm{AE}$ events during the whole loading process were recorded. The test system is shown in Figure 4. 


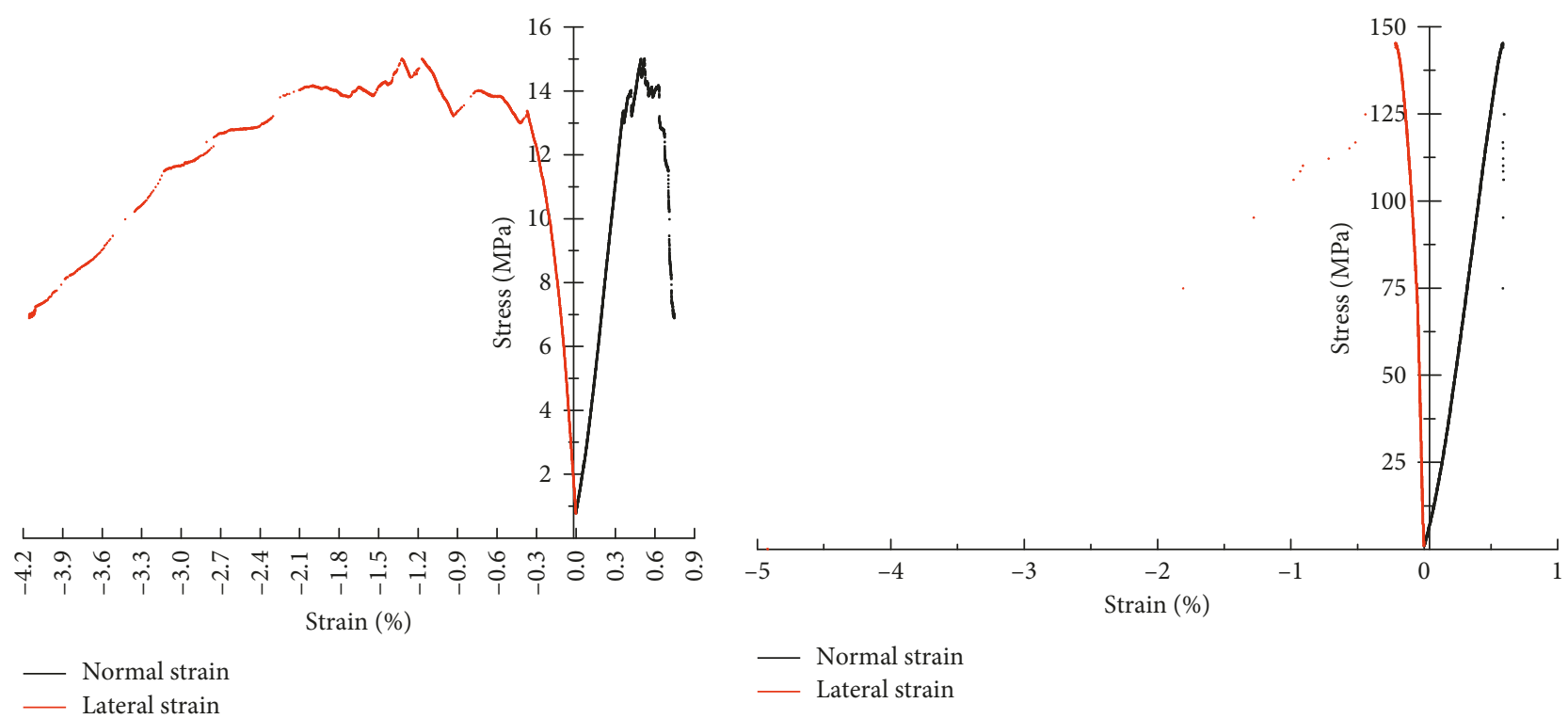

(a)

(b)

Figure 2: The stress-strain curves of individual coal and rock samples: (a) coal sample; (b) rock sample.

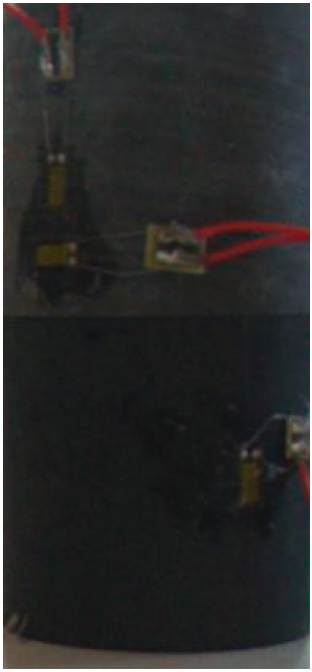

(a)

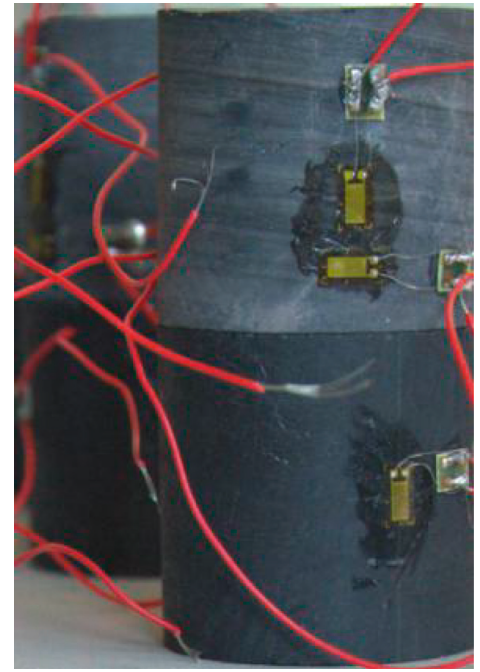

(b)
FIGURE 3: Samples before tested.

About the contact approach between coal and sandstone, other scholars mainly adopted artificial adhesive approach and natural contact approach, considering that the cohesion of coal-rock interface is relatively low, so the natural contact was adopted, smearing Vaseline between coal-rock interface as transmission coupling medium for AE signals.

\section{Failure Process and Acoustic Emission Characteristics of Combined Samples}

3.1. Stress-Strain Relationship Analysis of Combined Samples. The peak strength and elastic modulus of each sample are shown in Figure 5, where $E$ represents the overall elastic modulus of combined samples. The black curve showed a clear peak of elastic modulus with the increase of loading rates, and the variation of the elastic modulus under different loading rates is erratic, which was probably caused by the influence of rock mass compaction and interface closure. When the loading rate was relatively low, the strength of the combined samples was close to the strength of pure coal samples. With the increase of the loading rate, the strength of the combined samples ranged from $11 \mathrm{MPa}$ to $24 \mathrm{MPa}$, increasing with the increase of the loading rate in the selected loading rate range, while the elastic modulus showed a trend of high on middle and low on both sides.

Typical stress-strain curves of combined samples are shown in Figure 6, where the strain values represent the axial strain of combined samples, namely, the sum of axial rock strain and axial coal strain. In general, the elastic modulus increases and the peak strain decreases with the increase of loading rate, while the peak strain with no obvious change, which is related to the uneven deformation caused by loading conditions and the stress adjustment process. In contrast, the compaction deformation of combined samples tended to be more obvious than the compaction deformation of pure coal samples, and the combined samples entered into the elastic stage faster with the increase of loading rates, and the insufficient compaction increased the stress adjustment ability near the peak strength of the sample to a certain extent.

With the change of the loading rate, failure process presented three different patterns. When the loading rates were $0.006 \mathrm{~mm} / \mathrm{min}$ and $0.012 \mathrm{~mm} / \mathrm{min}$, the plastic deformation of the coal mass was fully developed, and the slip along the transfixion crack surface occurred in the postpeak stage. When the loading rates were $0.03 \mathrm{~mm} / \mathrm{min}$ and $0.04 \mathrm{~mm} / \mathrm{min}$, the plastic crack was not fully developed at the prepeak stage. At the end of the prepeak stage and the whole 


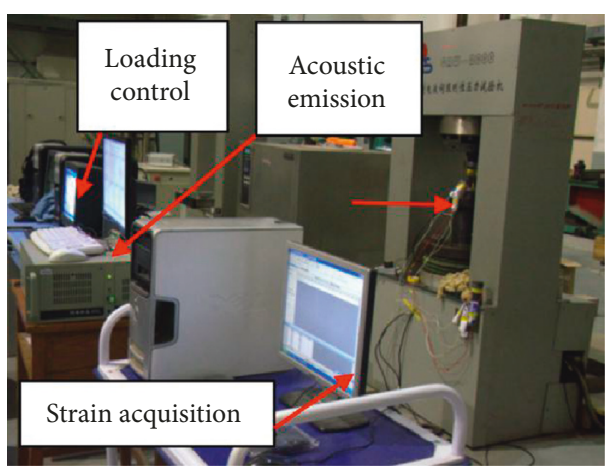

(a)

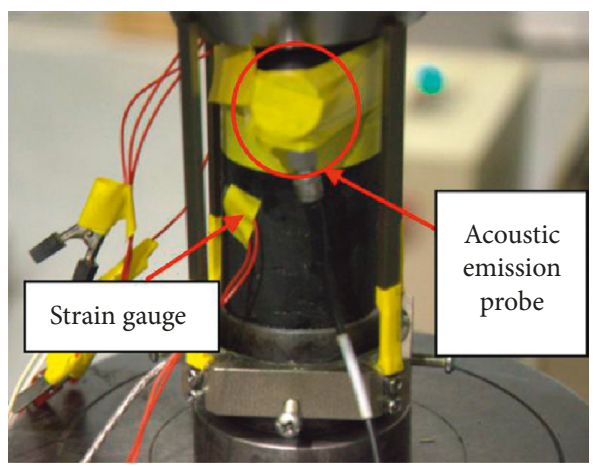

(b)

Figure 4: Testing system: (a) testing equipment; (b) monitoring system.

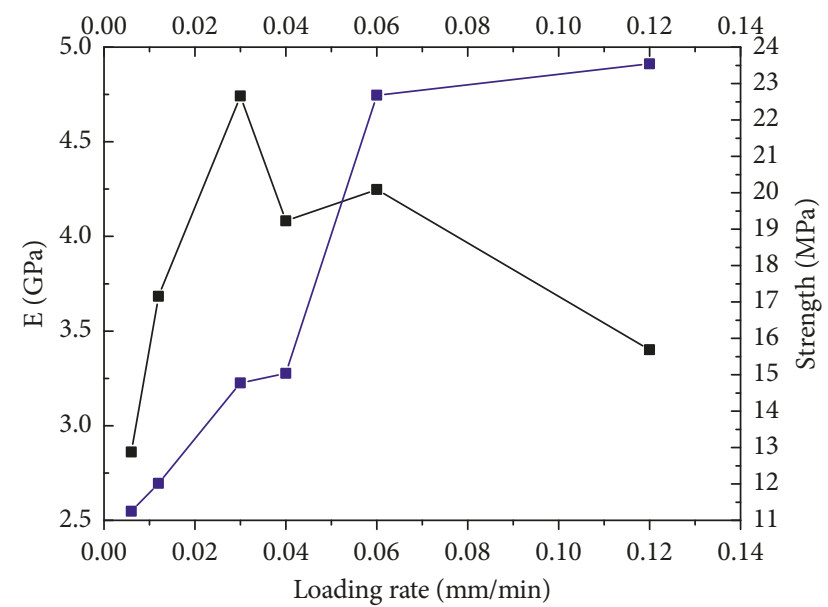

Figure 5: Statistics of elastic modulus and peak strength.

postpeak stage, stress of coal mass was under constant adjustment process until the final instability of crack structure. At the loading rates of $0.06 \mathrm{~mm} / \mathrm{min}$ and $0.12 \mathrm{~mm} / \mathrm{min}$, larger loading rate led to the result that the coal mass stress could not adjust to the changing load, and finally the brittle failure occurred suddenly under the effect of the energy release of upper rock mass and the coal mass.

It is observed from Figures 6(a) to 6(c) that the deformation process of $1^{\#}$ and $2^{\#}$ sample was relatively gentle, and the coal mass was finally destroyed along the crack surface, while the deformation of rock mass was relatively small and even released. Step-shaped strain release of the rock mass in $3^{\#}$ and $4^{\#}$ combined samples was obtained during the release of elastic energy at postpeak stage, and this situation was more intuitively expressed in the strain process of the rock mass in $4^{\#}$ sample. Due to the relatively large loading rate, the rock mass of $5^{\#}$ and $6^{\#}$ sample presented one-time strain release when elastic energy released in the suddenly failure of coal mass, which also led to a relatively more violent destruction.

The strain curves of strain gauges in different parts show different characteristics, corresponding to the stressstrain curves. When the loading rate was $0.012 \mathrm{~mm} / \mathrm{min}$, the strain curves of both coal mass and rock mass were relatively smooth, and strain of coal mass decreased ahead of the final damage due to local failure of coal mass, and the overall strain and the strain of rock mass suddenly descended at the time of suddenly failure. When the loading rates were $0.03 \mathrm{~mm} / \mathrm{min}$ and $0.04 \mathrm{~mm} / \mathrm{min}$, cracks developed fully and the strain of the rock mass was linear at the prepeak stage, presenting step-shaped strain release at postpeak stage, which was accompanied by the repeated cracks in the coal mass. At the loading rate of $0.06 \mathrm{~mm} / \mathrm{min}$ and above, the monitoring strain of the coal mass generally had a mutation before the overall damage occurred, accompanied by sudden collapse of the rock mass as rapid loading on coal mass.

3.2. Failure Characteristics of Combined Samples. In general, the instability of coal-rock mass begins to appear when the loading on coal-rock mass exceeds the peak strength. With the increase of loading rate, peak strength of rock materials tends to increase to a certain extent; while at the same time, high loading rate causes the decreasing ability of rapidly deformation adjustment when reaching higher strength. Therefore, along with the increase of loading rate, strength and brittleness of coal mass increase, and the ductility of the rock mass will generally reduce accordingly. The original cracks in the upper part of the hard mass determine the deformation ratio of the two bodies during compaction.

Strain gauges for coal lost efficacy when the located region shattered, and several undamaged gauges were chosen for whole process analysis. The deformation and failure of the samples showed obvious development process, and axial strain curves of three samples are shown in Figure 7. The surface crack of the $2^{\#}$ sample was not obvious, and the eventually crack is shown in Figure 8. For $3^{\#}$ sample and $4^{\#}$ sample, development of surface splitting resulted in the loss of bearing capacity. For $5^{\#}$ sample, the tensile cracks on surface coal were accompanied by the weakening of the internal bearing structure under the large loading rate, resulting in sudden instability as a whole. The above phenomenon is consistent with the classic conclusion: the physical and mechanical properties of combined sample is relative to the loading conditions, such as uniaxial 


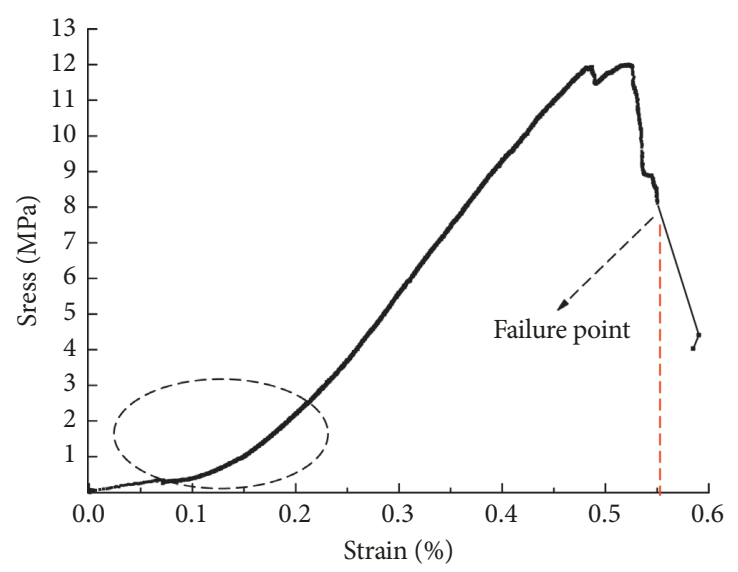

(a)

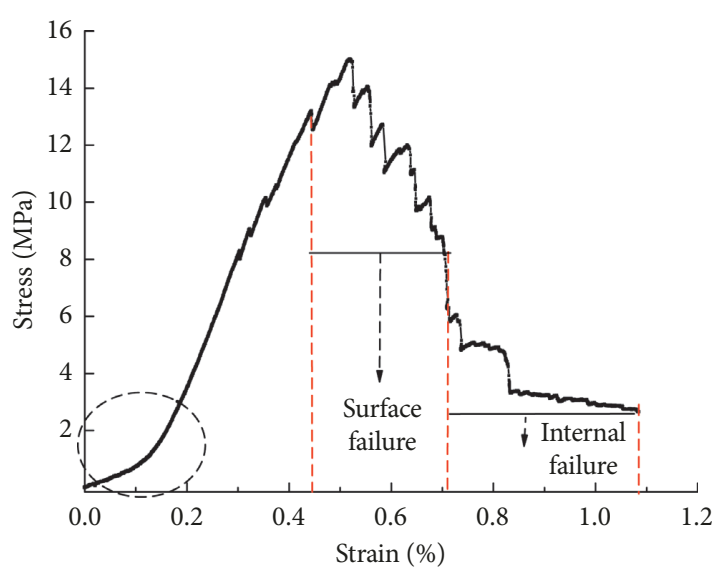

(b)

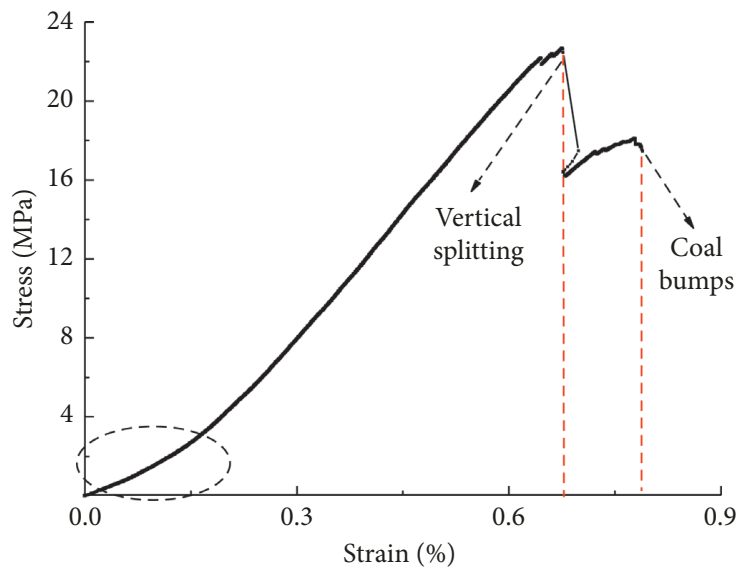

(c)

Figure 6: Stress-strain curves of combined samples: (a) $1^{\#}$ combined sample; (b) $3^{\#}$ combined sample; (c) $5^{\#}$ combined sample.

compressive strength, peak strength, failure characteristics, and stress-strain relationship, while the dissipation and release law of elastic energy is relative to the combining form of samples.

\subsection{Acoustic Emission Characteristics Analysis of Progressive} Shear Failure Sample. According to the definition and descriptive angle of the parameters, AE parameters can be divided into process parameters and state parameters. Process parameters describe the whole AE monitoring process, reflecting the overall behavior of the process, while state parameters reflect the instantaneous AE characteristics during the process. In common, cumulative parameters (such as cumulative number of events, ringing counts, and cumulative release energy) and statistical parameters (such as amplitude distribution, frequency distribution, and rising time distribution) are all process parameters, while the rate of $\mathrm{AE}$ events, $\mathrm{AE}$ rate, and energy releasing rate are common state parameters. With combination of the test results, the AE characteristic curves, as shown in Figure 9, demonstrate the count of AE events and cumulative energy.

When the loading rate was $0.012 \mathrm{~mm} / \mathrm{min}$, the count and the cumulative energy of AE events slightly developed in the prepeak stage, while the count was generally small and the growth of cumulative energy was slow. Along with stress adjustment at the postpeak stage, the through surface formed and eventually failed with the development of plastic deformation and cracks. The relative intensity of AE was obviously lower than that of other combined samples, and the ultimate destruction of the sample was relatively calm.

The energy release rate is defined as the energy value of AE events per unit time, which can be expressed as the slope of the cumulative energy curve in the figure, mainly in the form of periodic linear growth and transient growth.

\subsection{Acoustic Emission Characteristics Analysis of Splitting} Failure Samples. When the loading rate was $0.03 \mathrm{~mm} / \mathrm{min}$, the count and the cumulative energy were low at prepeak stage, and the cumulative energy was almost stagnant. At the postpeak stage, with stress adjustment and periodic destruction of coal mass, the cumulative energy continued to increase, and AE events occurred periodically in the course of constant stress adjustment. The AE events could be divided into two stages by intensity; the energy release at first stage was more intense, and the intensity of AE events decreased after a large stress drop and energy dissipation and entered into the second stage. Eventually, after a number of intermittent energy release, the sample underwent 


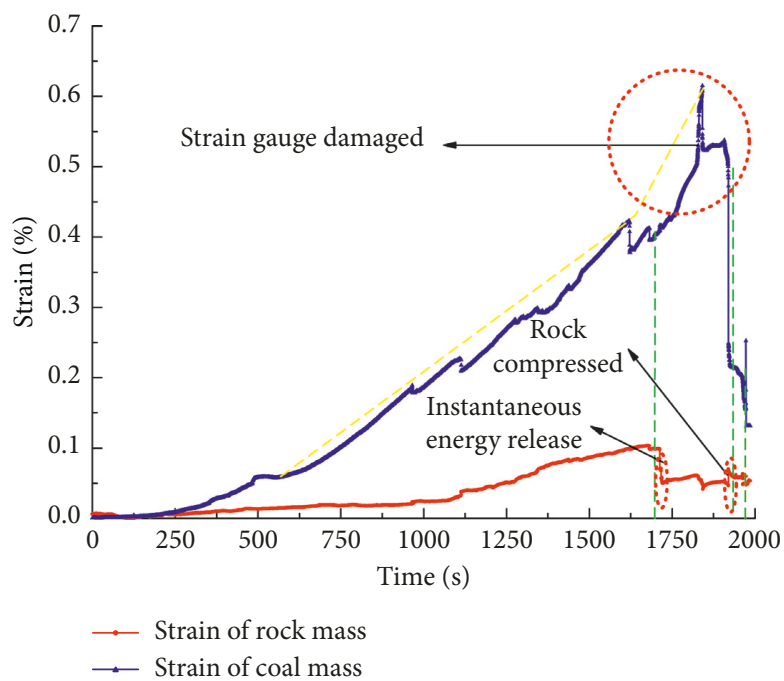

(a)

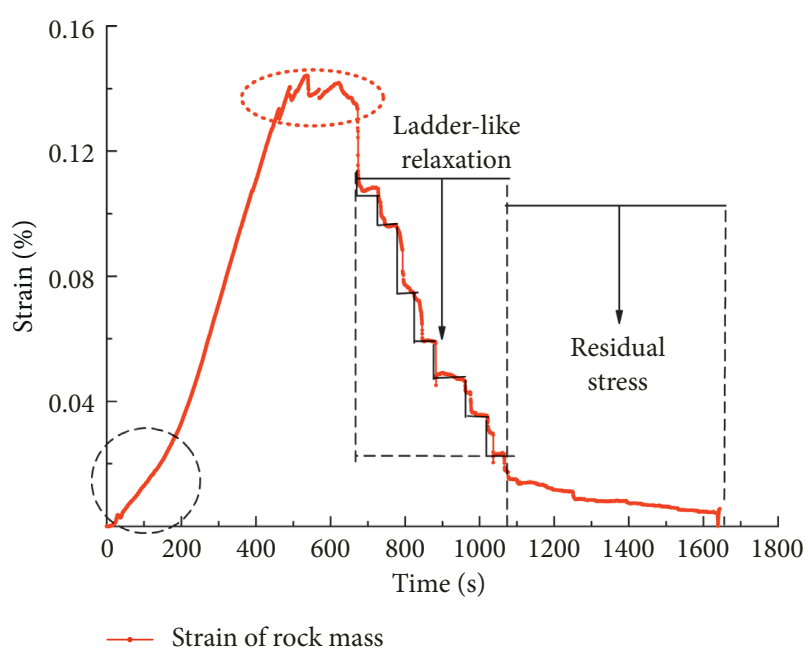

(b)

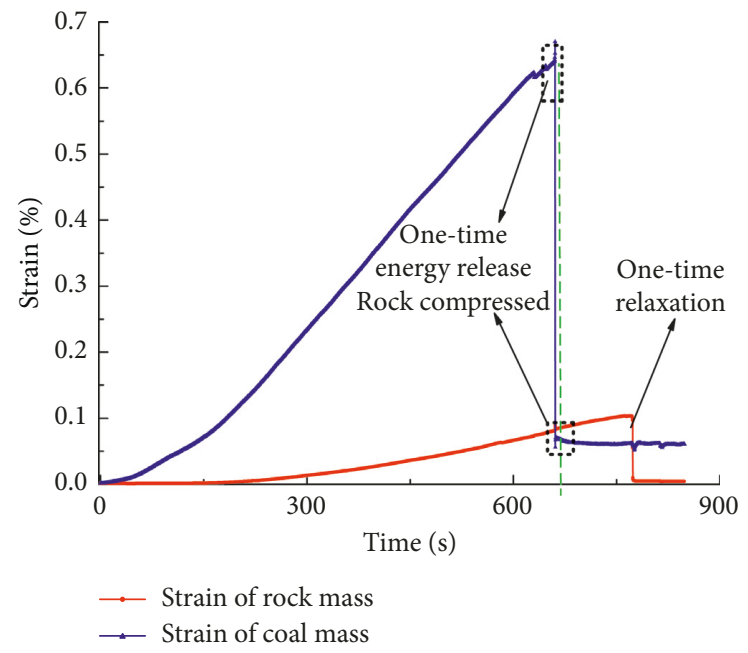

(c)

Figure 7: Axial strain curves: (a) intermediate sample ( $\left.3^{\#}\right)$; (b) step-shaped strain release of rock mass ( $\left.4^{\#}\right)$; (c) one-time strain release of rock mass $\left(5^{\#}\right)$.

a relatively calm slip along the splitting cracks. The AE events before the peak of the sample were distributed evenly, and the burst degree after the peak was also more moderate. The $\mathrm{AE}$ characteristics of $3^{\#}$ sample are shown in Figure 10.

At the same time, it could be seen that the $\mathrm{AE}$ events in each stage were generally ahead of the stress drop, which indicated that the destruction of the samples had certain viscosity characteristics, leading to the delay of energy dissipation.

3.5. Acoustic Emission Characteristics Analysis of Structural Failure Samples. AE characteristics of $5^{\#}$ sample are shown in Figure 11. When the loading rates were $0.06 \mathrm{~mm} / \mathrm{min}$ and $0.12 \mathrm{~mm} / \mathrm{min}$, the AE count was generally small at the prepeak stage, and the increasing rate of the cumulative energy was also slow. The stress could not adjust to the energy release slowly and the it dropped abruptly near the peak and rose a little higher subsequently. AE events count and energy value were high in the postpeak stage, and brittle failure finally happened under the effect of sustained energy release.

\section{Failure Modes and Mutation Process of Combined Samples}

4.1. Frequency Distribution Characteristics of Combined Samples. The peak amplitude of the AE waveform can describe the intensity of $\mathrm{AE}$ events, and the time-peak frequency curves of typical samples are shown in Figure 12.

It can be seen from the curves that there are two distinct frequency bands, which are about $50 \mathrm{kHz}$ and $150 \mathrm{kHz}$, respectively. Considering that the peak frequency of rock cracks development is larger than that of coal mass and the distribution of $\mathrm{AE}$ events near $50 \mathrm{kHz}$ are larger and stronger, the two frequency bands are the main frequency range of coal and rock mass, respectively. 


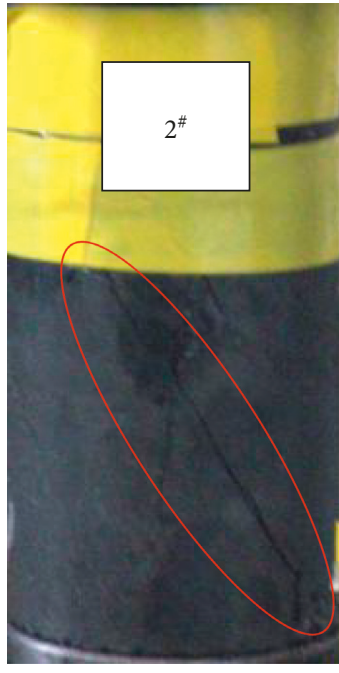

(a)

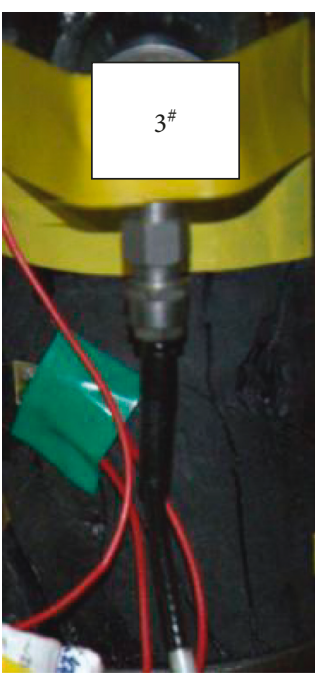

(b)

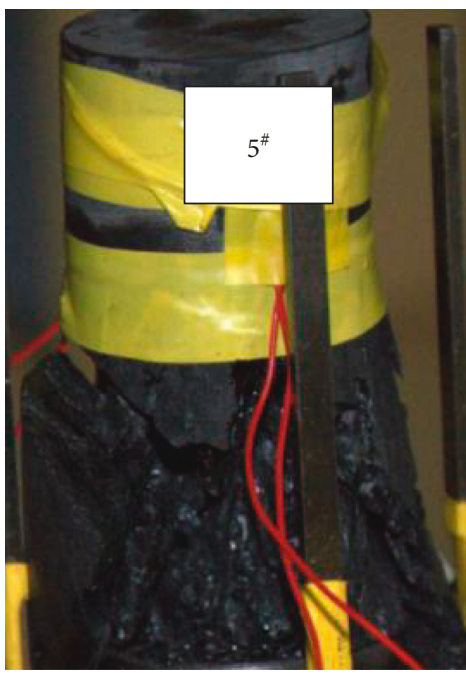

(c)

Figure 8: The failure characteristics of coal mass: (a) transfixion crack; (b) surface splitting; (c) overall instability.

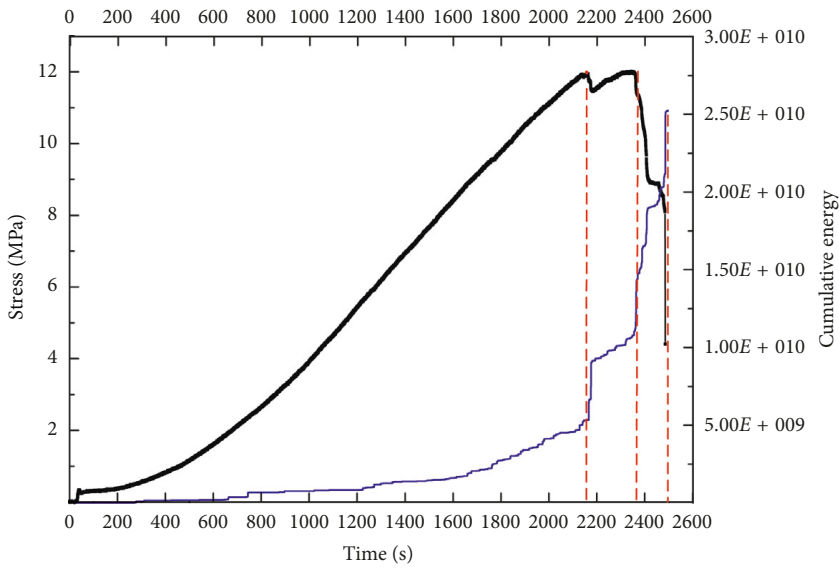

(a)

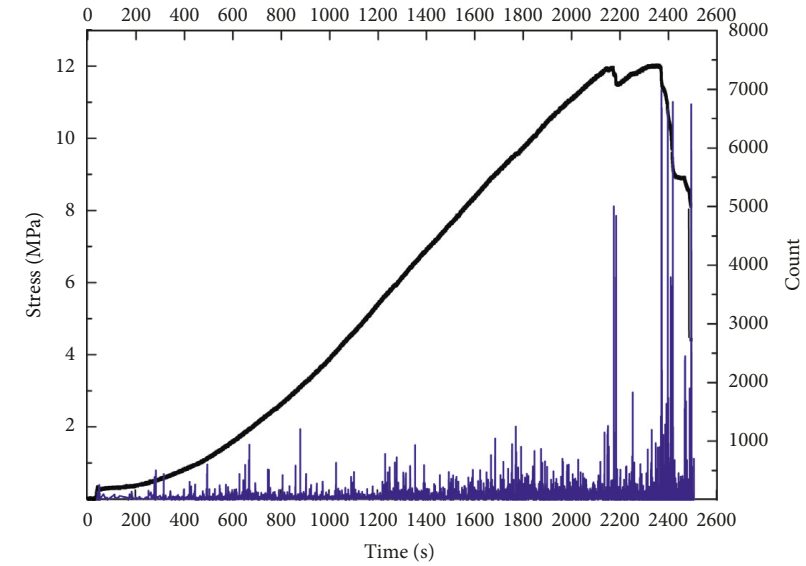

(b)

Figure 9: Acoustic emission characteristics of $2^{\#}$ sample: (a) cumulative energy; (b) count.

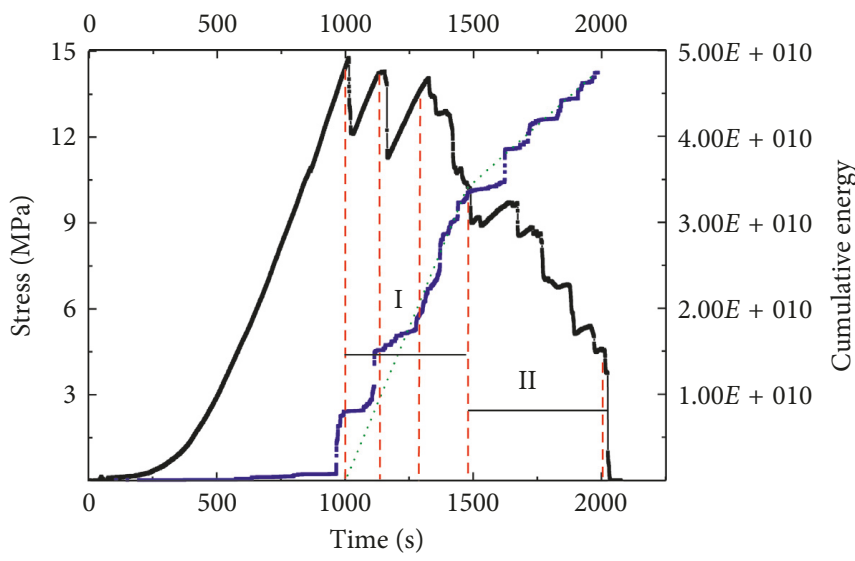

-.- Stress

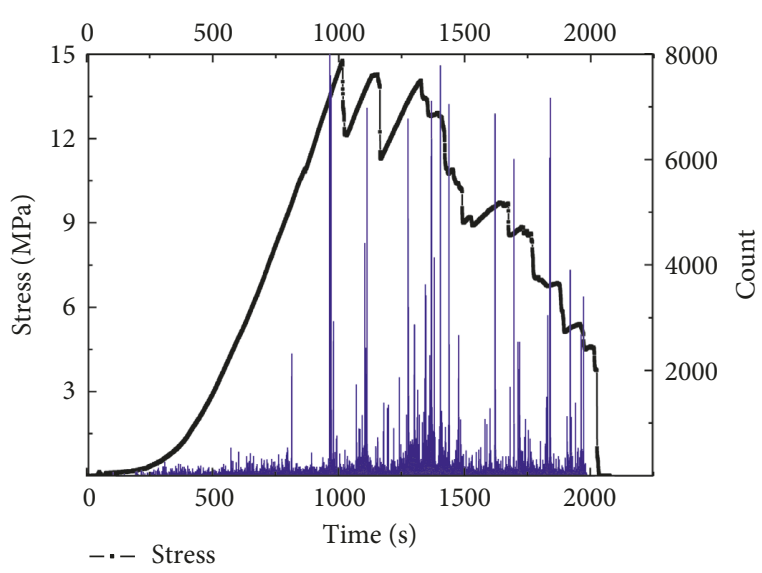

(b)

Figure 10: Acoustic emission characteristics of $3^{\#}$ sample: (a) cumulative energy; (b) count. 


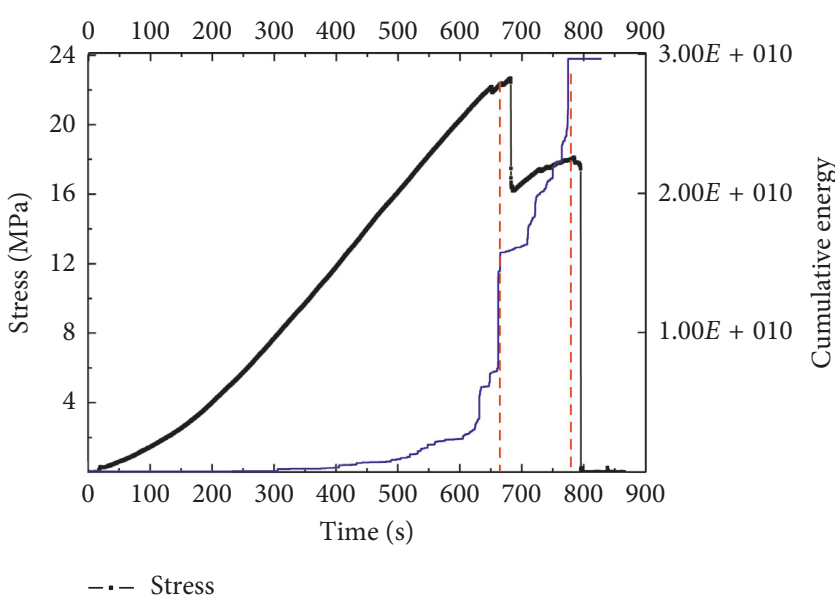

(a)

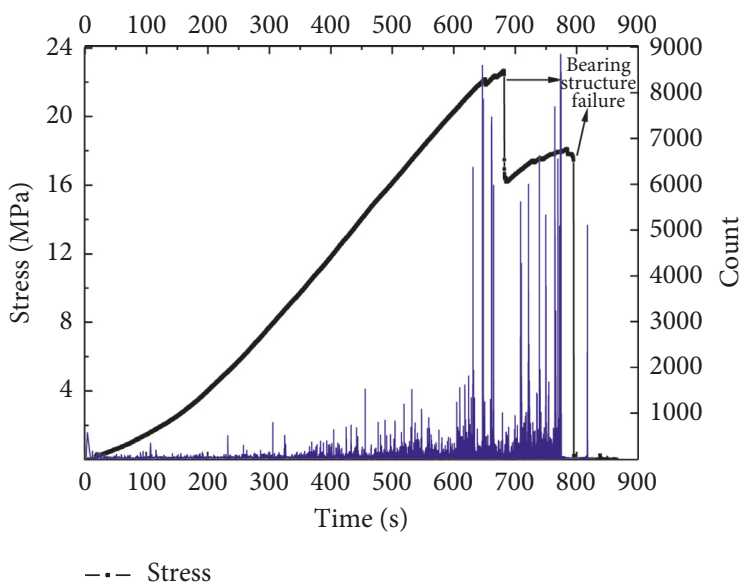

(b)

Figure 11: Acoustic emission characteristics of $5^{\#}$ sample: (a) cumulative energy; (b) count.

The scatter points between the main frequency bands can be approximated and viewed as AE events caused by the failure of bearing structure in coal mass, and the frequency values are also slightly higher than the AE events caused by the microcracks in the coal mass. With the loading rate increasing, the scatter distribution was more concentrated and the frequency value increased.

When the loading rate was relatively low, there was a relatively obvious low frequency band for $2^{\#}$ sample, which could be regarded as the result of the original cracks closure.

4.2. Failure Modes Analysis of Combined Samples. The amplitude of bearing structure damage is basically between 45 and $65 \mathrm{~dB}$. From the failure characteristics of the samples shown in Figure 8 , the frequency range of $2^{\#}$ sample is basically flat expanding, and the peak frequency of AE events increases with the destruction of bearing structure. The high peak frequency of $\mathrm{AE}$ events in coal mass of $3^{\#}$ and $4^{\#}$ samples are mainly concentrated in the ladder-like changing region of stress, and the bearing structure of the sample is destroyed constantly during the stress adjustment process until the eventual failure. The high peak frequency of $\mathrm{AE}$ events in coal mass of $5^{\#}$ emerged after the peak and are more concentrated, representing the rapid destruction of bearing structure.

The failure of the samples showed obvious development process. Surface cracks of $2^{\#}$ sample are not apparent, and finally transfixion crack is shown in Figure 8. Splitting cracks of $3^{\#}$ sample and $4^{\#}$ sample kept developing on the coal surface, resulting in structural loss of bearing capacity. In the case of $5^{\#}$ sample, the surface coal mass was torn under a large loading rate, and the whole structure suddenly became unstable with the weakening of the internal bearing structure.

With the increase of loading rate, the release of energy became more violent, and the total energy released was related to the stiffness of the coal at the postpeak stage. The internal microcracks of inner rock mass were further expanded due to the stress concentration during the loading process, and brittle cracks occurred along the direction of minimum energy dissipation when extended to the critical crack size. The thinner zone of coal seam caused sharp change of the rigidity ratio of coal to rock and the increased thickness of the hard roof hindered the transfer of stress, and the test results matched well with the coalsandstone combination in coal bump area. Three typical failure modes of the combined samples are shown in Figure 13.

4.3. Mutation Process Analysis. The failure of rock mass follows the composite failure criterion of shear failure and tensile failure, and the mechanical behavior after failure is between strain softening and ideal plasticity. The deformation development and failure of coal-rock combination is a nonlinear process, and the catastrophe theory can better cover the singularities and bifurcations in the nonlinear system, as a more mature nonlinear theory.

In theory, when the loading rate is very slow, the samples have sufficient deformation adjustment time, with no sudden release of energy. When the loading rate is high, the energy dissipation cannot be completely offset by continuous plastic strain, and energy is rapidly released in the form of crack development. The upper hard mass can be regarded as an elastomer, and the lower soft mass can be regarded as a damaged elastomer [20]. Considering stress continuous conditions, there are following stress-strain relationships, respectively:

$$
\left\{\begin{array}{l}
F_{1}=K_{1} u_{1}, \\
F_{2}=K_{2} u_{2} \cdot \exp \left[-\left(\frac{u_{2}}{u_{0}}\right)^{m}\right], \\
F_{1}=F_{2},
\end{array}\right.
$$

where $F_{1}$ and $F_{2}$ represent the axial force of rock and coal, respectively, $K_{1}$ and $K_{2}$ represent the axial stiffness of rock 


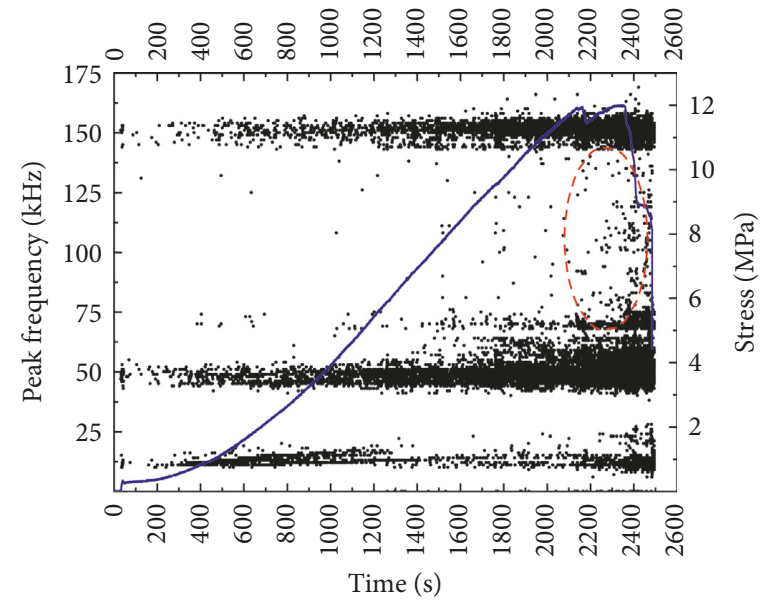

(a)

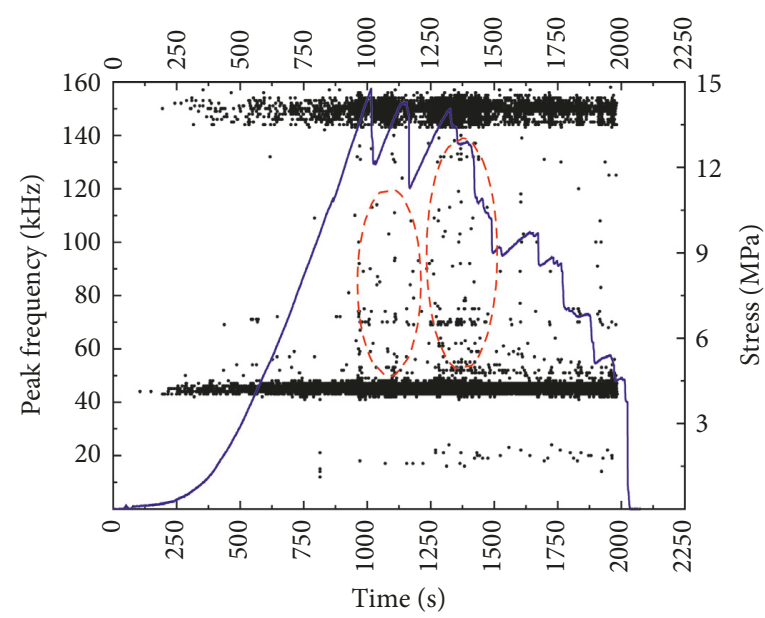

(b)

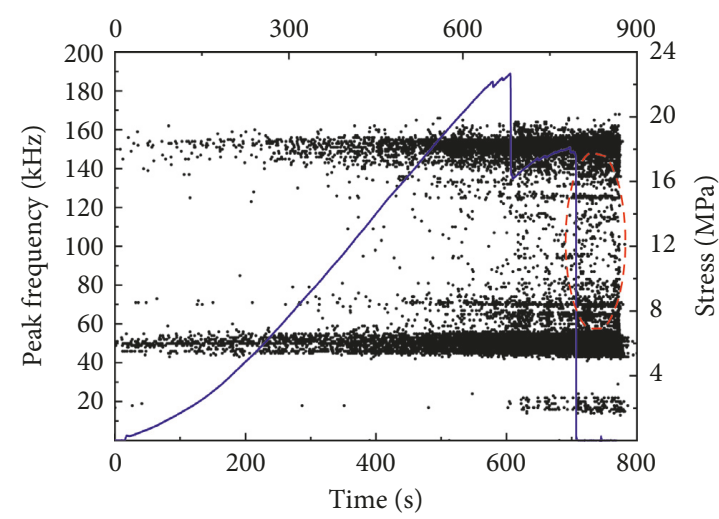

(c)

FIgURE 12: The distribution of frequency: (a) $2^{\#}$ combined sample; (b) $3^{\#}$ combined sample; (c) $5^{\#}$ combined sample.

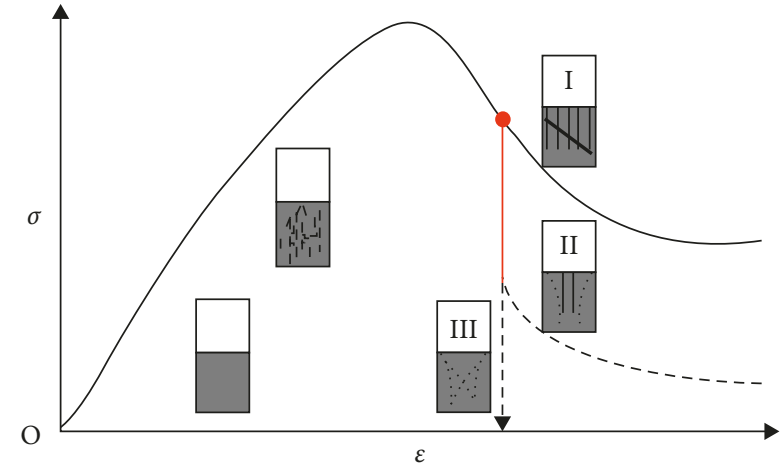

Figure 13: Possible failure modes.

and coal, respectively, $u_{1}$ and $u_{2}$ represent the axial displacement of rock and coal, respectively, while $u_{0}$ and $m$ are distributed variables.

Many scholars simplify the vertical deformation of the upper structure as the difference between the total deformation and the deformation of the lower structure. However, the total deformation is not a constant but a function of the lower deformation. Considering that the gravity of sample is almost negligible compared with axial load, the change of the geopotential energy of the combined structure is relatively small. Therefore, we can just consider the elastic deformation energy in the calculation of potential energy function, and geopotential energy of the system is neglected; the total potential energy function of the system is as follows:

$$
V\left(u_{2}\right)=\int_{0}^{u_{1}} K_{1} u_{1} \cdot d u_{1}+\int_{0}^{u_{2}} K_{2} u_{2} \cdot \exp \left[-\left(\frac{u_{2}}{u_{0}}\right)^{m}\right] d u_{2} .
$$

The essential condition for brittle failure of coal mass in combined coal-rock structure is that the rigidity of the coal mass is larger than that of the rock mass. At the same time, the energy input rate $J=0$, namely, that the energy condition for potential coal bumps is fulfilled and we get

$$
F^{\prime}\left(u_{2}\right)_{V^{\prime}}\left(u_{2}\right)=0=-K_{1}
$$

4.4. Components Combination Model. In theory, there is a brittle catastrophe model of the coal-rock combination as shown in Figure 14. With the increasing stiffness ratio of rock to coal, the release of energy is more sudden and violent, and the total energy released is related to the stiffness 


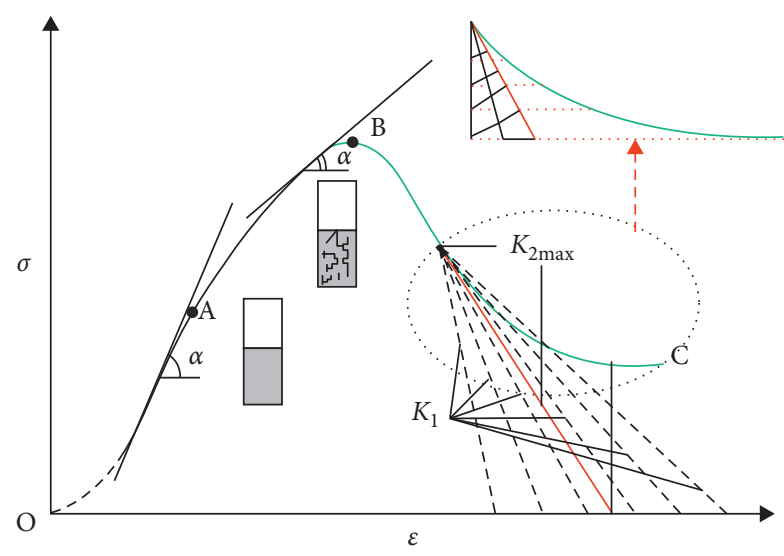

FIgURE 14: Brittle catastrophe model.

of the coal at the postpeak stage. The mechanical properties of rock are the comprehensive reflection of elastic, plastic, viscous, brittle, and other properties under different loading conditions, and single stress-strain relationship could not explain the real boundaries of the mutation under different loading conditions and combination conditions due to the hysteresis of the mutation.

In order to describe the gradual failure and stress adjustment characteristics of the coal-rock masses, a mutation elements model with damage and stick-brittle characteristics was established according to the failure characteristics of the combined sample, as shown in Figure 15. In the model, the upper rock mass was simplified as elastic mass, while the lower coal mass represented by an infinite number of elasticbrittle microunits with strength in accordance with the Weibull distribution and a representative sticky-brittle element for the main structure in parallel.

The damage process of the main structure is different under different loading conditions. Considering that the overall stiffness of thick rigid roof is generally dozens of times larger than that of the coal seam, which greatly increases the risk of coal bumps. With different loading conditions, the number of fragile microunits per unit time and the concentration of energy release also change accordingly, and the probability of mutation is also different on the basis of the mutation condition. The intensity degree of failure can be divided into progressive shear failure, splitting failure, and structural failure.

\section{Conclusions}

Considering the combined coal-rock structure for coal bumps, failure process and AE characteristics of combined coal-sandstone samples during compression tests were studied under different loading rates within $0.006 \mathrm{~mm} /$ $\mathrm{min} \sim 0.12 \mathrm{~mm} / \mathrm{min}$, and three basic failure modes and bump proneness for coal-rock structure were obtained.

(i) Within the selected loading rate range, the strength of combined samples ranged from $11 \mathrm{MPa}$ to $24 \mathrm{MPa}$, having an increase trend with the increase of the loading rate, while the elastic modulus presented a trend of high on middle and low on both

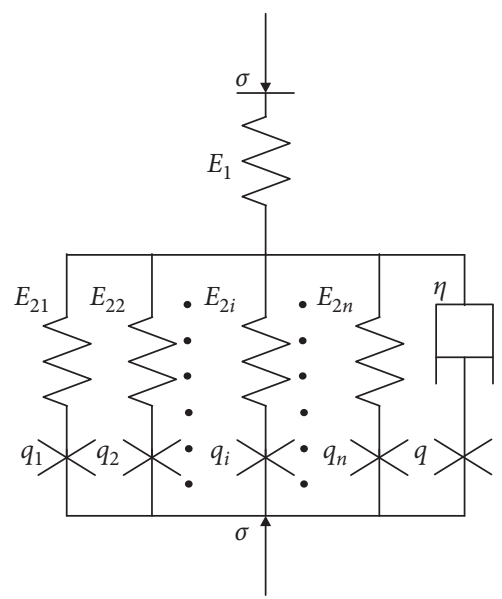

FIGURE 15: Combination elements model.

sides. When the loading rates were $0.006 \mathrm{~mm} / \mathrm{min}$ and $0.012 \mathrm{~mm} / \mathrm{min}$, the plastic deformation of the coal mass was fully developed, and the slip along the transfixion crack surface occurred in the postpeak stage. When the loading rates were $0.03 \mathrm{~mm} / \mathrm{min}$ and $0.04 \mathrm{~mm} / \mathrm{min}$, the plastic crack was not fully developed in the prepeak stage. At the end of the prepeak stage and the whole postpeak stage, stress inner coal mass was under the constant adjustment process until the final crack structure instability. At the loading srate of $0.06 \mathrm{~mm} / \mathrm{min}$ and $0.12 \mathrm{~mm} / \mathrm{min}$, the coal mass stress could not adjust to the increasing load slowly with surface tensile cracks developing, and brittle failure finally happened under the effect of sustained energy release of upper rock mass and the coal mass with internal bearing structure damaged.

(ii) The deformation and failure process of combined samples showed obvious phases, and corresponding AE energy release rate could be divided into periodic linear growth and transient growth in the whole process of uniaxial compression, while the cumulative energy of AE events has multiple peak points or transient growth with the increase of the loading rate. When the loading rate was $0.012 \mathrm{~mm} / \mathrm{min}$, surface cracks of coal mass was not apparent, and finally slip along the transfixion crack surface occurred in the postpeak stage. Splitting cracks of $3^{\#}$ sample and $4^{\#}$ sample kept developing in the coal surface, and the intensity of AE events decreased after a large stress drop and energy dissipation and entered the second stage, resulting in structural loss of bearing capacity. Eventually, after a number of intermittent energy release, the sample underwent a relatively calm slip along the splitting cracks. When the loading rates were $0.06 \mathrm{~mm} / \mathrm{min}$ and $0.12 \mathrm{~mm} / \mathrm{min}$, surface tensile cracks developed, while AE count and the increasing rate of the cumulative energy were generally small in the prepeak stage; brittle failure finally happened under the effect of sustained energy release of upper rock 
mass, and the coal mass with internal bearing structure damaged in the postpeak stage.

(iii) It was demonstrated that two distinct frequency bands existed in $\mathrm{AE}$ events, which were about $50 \mathrm{kHz}$ and $150 \mathrm{kHz}$, and the distribution of $\mathrm{AE}$ events near $50 \mathrm{kHz}$ was larger and stronger, representing the main frequency range of cracks in coal mass. According to the damage characteristics and AE parameters of combined samples, the brittle model for coal-rock combination with damage and mutation characteristics was proposed. Three basic failure modes for combination with the increase of loading rate were progressive shear failure, splitting failure, and structural failure, respectively.

\section{Data Availability}

The data used to support the findings of this study are available from the corresponding author upon request.

\section{Conflicts of Interest}

The authors declare that they have no conflicts of interest.

\section{Acknowledgments}

This research was supported by Linyi University (No. LYDX2016BS108). The authors would like to thank Drs. Tao Wang and Xueling Du for their valuable contribution to this paper.

\section{References}

[1] Y. Jiang, Y. Zhao, H. Wang, and J. Zhu, "A review of mechanism and prevention technologies of coal bumps in China," Journal of Rock Mechanics and Geotechnical Engineering, vol. 9, no. 1, pp. 180-194, 2017.

[2] H. Lippmann, "Mechanics of "bumps" in coal mines: a discussion of violent deformations in the sides of roadways in coal seams," Applied Mechanics Reviews, vol. 40, no. 8, pp. 1033-1043, 1987.

[3] E. Eberhardt, D. Stead, and B. Stimpson, "Quantifying progressive pre-peak brittle crack damage in rock during uniaxial compression," International Journal of Rock Mechanics and Mining Sciences, vol. 36, no. 3, pp. 361-380, 1999.

[4] N. Li, X. Feng, and R. Jimenez, "Predicting rock burst hazard with incomplete data using Bayesian networks," Tunnelling and Underground Space Technology, vol. 61, pp. 61-70, 2017.

[5] A. W. Khair, "An analysis of coal bump liability in a bump prone mine," International Journal of Mining Engineering, vol. 3, no. 4, pp. 243-259, 1985.

[6] J. Shepherd, L. K. Rixon, and L. Griffiths, "Outbursts and geological structures in coal mines: a review," International Journal of Rock Mechanics and Mining Sciences and Geomechanics Abstracts, vol. 18, no. 4, pp. 267-283, 1981.

[7] S. P. Singh, "Burst energy release index," Rock Mechanics and Rock Engineering, vol. 21, no. 2, pp. 149-155, 1988.

[8] A. T. Iannacchione and S. C. Tadolini, "Occurrence, predication, and control of coal burst events in the U.S," International Journal of Mining Science and Technology, vol. 26, no. 1, pp. 39-46, 2016.
[9] H. A. Kasani and R. J. Chalaturnyk, "Influence of high pressure and temperature on the mechanical behavior and permeability of a fractured coal," Energies, vol. 10, no. 7, p. 854, 2017.

[10] F. M. Boler, S. Billington, and R. K. Zipf, "Seismological and energy balance constraints on the mechanism of a catastrophic bump in the book cliffs coal mining district, Utah, USA," International Journal of Rock Mechanics and Mining Sciences and Geomechanics Abstracts, vol. 34, no. 1, pp. 27-43, 1997.

[11] K. G. Hinzen, "Comparison of seismic and explosive energy in five smooth blasting test rounds," International Journal of Rock Mechanics and Mining Sciences, vol. 35, no. 7, pp. 957-967, 1998.

[12] M. B. D. Aguado and C. González, "Influence of the stress state in a coal bump-prone deep coalbed: a case study," International Journal of Rock Mechanics and Mining Sciences, vol. 46, no. 2, pp. 333-345, 2009.

[13] Q. Sun, J. Zhang, Q. Zhang, and X. Zhao, "Analysis and prevention of geo-environmental hazards with high-intensive coal mining: a case study in China's western eco-environment frangible area," Energies, vol. 10, no. 6, p. 786, 2017.

[14] L. Jie, W. Enyuan, S. Dazhao, Y. Sheng-Li, and N. Yue, "Effects of rock strength on mechanical behavior and acoustic emission characteristics of samples composed of coal and rock," Journal of China Coal Society, vol. 39, no. 4, pp. 685691, 2014.

[15] T. B. Zhao, W. Y. Guo, C. P. Lu, and G.-M. Zhao, "Failure characteristics of combined coal-rock with different interfacial angles," Geomechanics and Engineering, vol. 11, no. 3, pp. 345-359, 2016.

[16] J. Zuo, Z. Wang, H. Zhou, J. Pei, and J. Liu, "Failure behavior of a rock-coal-rock combined body with a weak coal interlayer," International Journal of Mining Science and Technology, vol. 23, no. 6, pp. 907-912, 2013.

[17] P. J. Jin, E. Y. Wang, and D. Z. Song, "Study on correlation of acoustic emission and plastic strain based on coal-rock damage theory," Geomechanics and Engineering, vol. 12, no. 4, pp. 627-637, 2017.

[18] Q. B. Zhang and J. Zhao, "A review of dynamic experimental techniques and mechanical behaviour of rock materials," Rock Mechanics and Rock Engineering, vol. 47, no. 4, pp. 1411-1478, 2014.

[19] X.-N. Wang, C.-P. Lu, J.-H. Xue et al., "Experimental research on rules of acoustic emission and microseismic effects of burst failure of compound coal-rock samples," Rock and Soil Mechanics, vol. 34, no. 9, pp. 2569-2575, 2013.

[20] J. A. Hudson and J. P. Harrison, Engineering Rock Mechanics: An Introduction to the Principles, Elsevier Science Inc., New York, NY, USA, 1997.

[21] S. Qin, J. J. Jiao, C. A. Tang et al., "Instability leading to coal bumps and nonlinear evolutionary mechanisms for a coalpillar-and-roof system," International Journal of Solids and Structures, vol. 43, no. 25-26, pp. 7407-7423, 2006.

[22] ASTM D388, Standard Classification of Coals by Rank, ASTM InternationalPenn., West Conshohocken, PA, USA, 2014. 


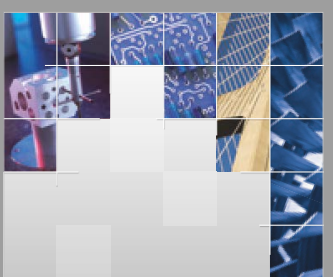

\section{Enfincering}
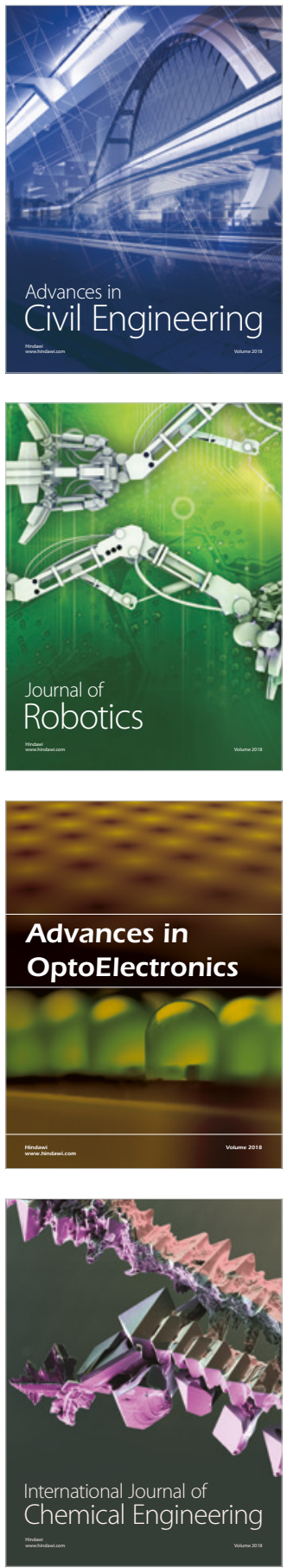

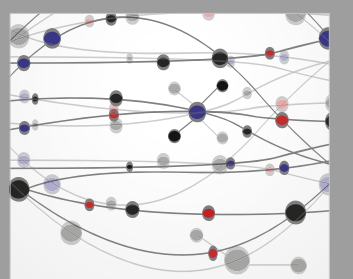

\section{Rotating \\ Machinery}

The Scientific World Journal

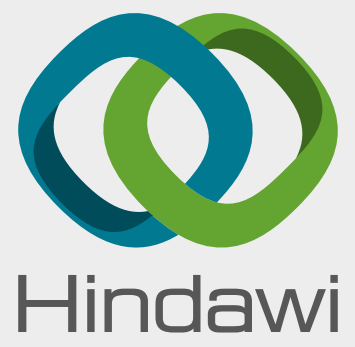

Submit your manuscripts at

www.hindawi.com
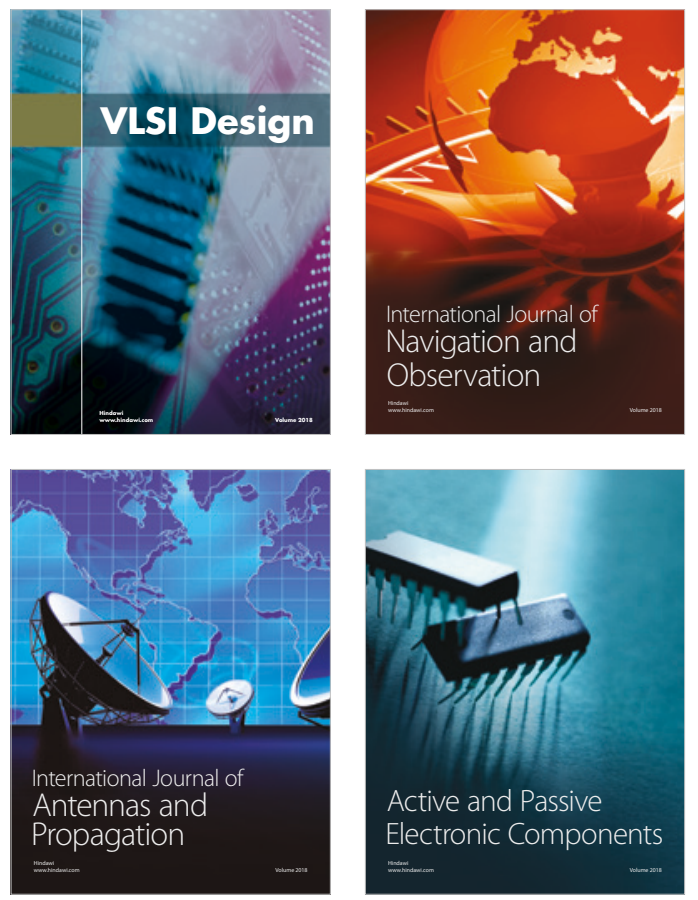
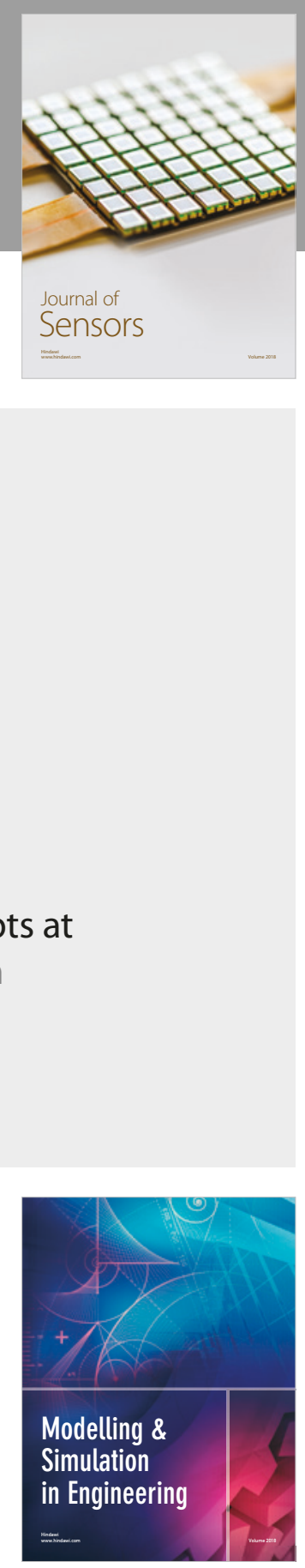

\section{Advances \\ Multimedia}
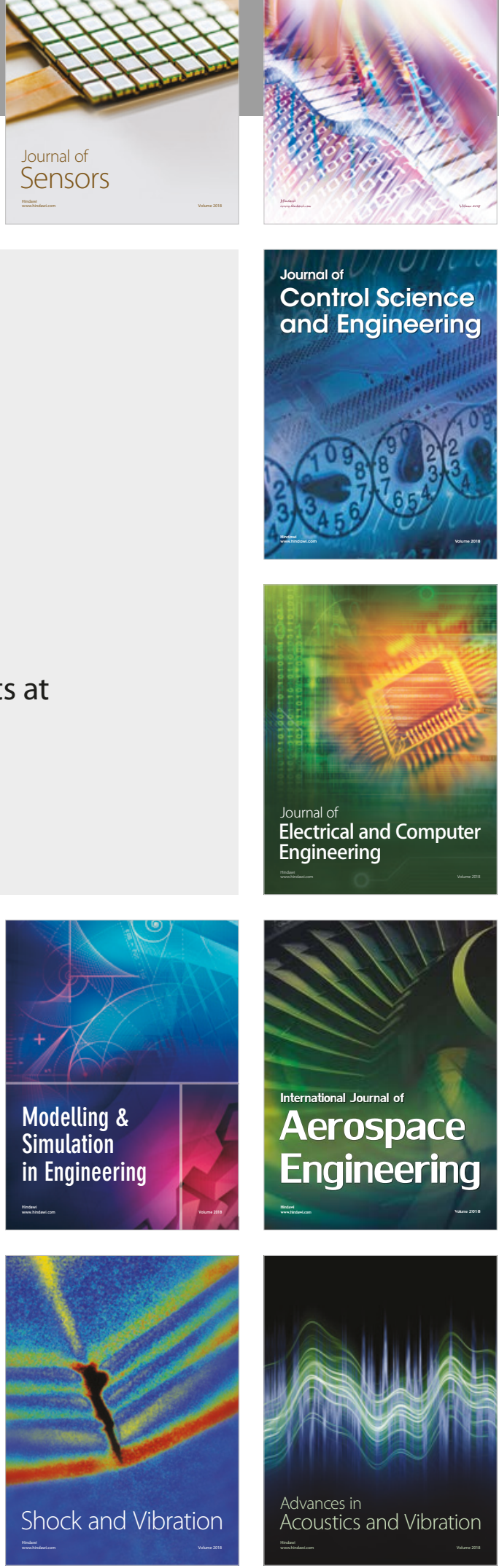